\title{
Does domestic violence during pregnancy influence the beginning of complementary feeding?
}

Gabriele Luiza Caprara* (ㅁ) Juliana Rombaldi Bernardi, Vera Lúcia Bosa, Clécio Homrich da Silva and Marcelo Zubaran Goldani

\begin{abstract}
Background: This study investigate the influence of domestic violence against pregnant women on early complementary feeding and associated factors.

Methods: A longitudinal observational study was conducted with a convenience sample recruited from three public hospitals in Porto Alegre, Rio Grande do Sul, Brazil. Data on maternal age, education, marital status, breastfeeding, introduction of complementary feeding and domestic violence during pregnancy were investigated at four follow-ups points. Data on domestic violence was collected through a self-report questionnaire based on the Abuse Assessment Screen. The early introduction of complementary feeding, characterized as occurring before or at 3 months of life, was verified through a questionnaire prepared by the research group. Data analysis involved Student's t-test, the chi-square test and Cox regression and was carried out in Statistical Package for the Social Sciences program. The significance level was set at 5\%.

Results: A total of 232 mother-infant pairs participated in the analyses, and $15.1 \%$ of the mothers reported suffering some form of violence. Domestic violence was directly associated with maternal education, marital status, and health status during pregnancy. Domestic violence was not associated with maternal age or breastfeeding at 3 months after delivery. In the univariate analysis, domestic violence during pregnancy was associated with early complementary feeding (RR $=1.74 ; \mathrm{Cl}: 1.01-2.98)$. This effect disappeared after the model was adjusted in multivariate analysis.
\end{abstract}

Conclusions: There was no relationship between domestic violence during pregnancy and early complementary feeding.

Keywords: Domestic violence, Pregnancy, Postpartum period, Complementary feeding

\section{Background}

Violence against women is acknowledged worldwide as a public health concern and is a major risk factor for the long-term physical and mental health of women $[1,2]$.

Domestic violence during pregnancy is associated with health problems for both the mother and the newborn and may result in miscarriage [2-5], intrauterine growth

\footnotetext{
* Correspondence: gabriele.nutri@yahoo.com.br

Center for Child and Adolescent Health Studies - Hospital de Clínicas de Porto Alegre - Faculdade de Medicina, Universidade Federal do Rio Grande do Sul, Rua Ramiro Barcelos, 2350, Porto Alegre, RS 90035-903, Brazil
}

restriction, risk of prematurity, lower birth weight $[2,4,5]$, higher stress biomarker levels in the child [6], and repercussions on the mother's physical and emotional state [2-5], which impair the quality of motherhood and the mother's ability to address the child's needs, including feeding behavior [7].

Breastfeeding duration and practices may be influenced by many factors, including maternal age, education, stress, and depressive symptoms [7]. A number of studies have found that mothers who suffer domestic violence have lower breastfeeding intention and initiation [7], as well as

(c) The Author(s). 2020 Open Access This article is licensed under a Creative Commons Attribution 4.0 International License, which permits use, sharing, adaptation, distribution and reproduction in any medium or format, as long as you give appropriate credit to the original author(s) and the source, provide a link to the Creative Commons licence, and indicate if changes were made. The images or other third party material in this article are included in the article's Creative Commons licence, unless indicated otherwise in a credit line to the material. If material is not included in the article's Creative Commons licence and your intended use is not permitted by statutory regulation or exceeds the permitted use, you will need to obtain permission directly from the copyright holder. To view a copy of this licence, visit http://creativecommons.org/licenses/by/4.0/. The Creative Commons Public Domain Dedication waiver (http://creativecommons.org/publicdomain/zero/1.0/) applies to the data made available in this article, unless otherwise stated in a credit line to the data. 
earlier cessation of exclusive breastfeeding, than those who do not [7-10]. The prevalence of exclusive breastfeeding in children under 6 months is $41.6 \%$ worldwide [11]. In Brazil it is 41\%, with an average duration of 1.8 months, according to the Brazilian Ministry of Health's Second Breastfeeding Prevalence Survey in State Capitals and the Federal District [12].

World Health Organization and Brazilian Ministry of Health guidelines for infant feeding recommend exclusive breastfeeding during the first 6 months of life, followed by nutritionally adequate and safe complementary feeding and continued breastfeeding up to age two or older $[13,14]$. Complementary feeding refers to all solid or liquid foods offered to the infant in addition to breast milk [14]. It is known that the introduction of food prior to 4 months is associated with lifelong adverse health outcomes, such as cardiovascular diseases, food allergies, type 1 and 2 diabetes mellitus [15-17], obesity, and an increased risk of overweight [7, 18, 19]. Infants only reach the renal and gastrointestinal maturity necessary to receive and metabolize foods other than breast milk after 6 months of age [20].

In a study of Indian women and their children up to 6 months of age, the authors reported that mothers exposed to some form of domestic violence were more likely to offer solid foods to infants, but that this practice did not differ significantly according to exposure or nonexposure to violence [21]. However, few studies have investigated the relationship between domestic violence against mothers and the introduction of complementary feeding to their infants.

Therefore, the purpose of this study was to investigate the influence of domestic violence against pregnant women on early complementary feeding and associated factors.

\section{Methods}

\section{Sample and data}

This longitudinal observational study, nested in a project called "Impact of variations of the perinatal environment on the health of newborns in the first 6 months of life" (IVAPSA) [22, 23] was approved by the Research Ethics Committees of Hospital de Clínicas de Porto Alegre (HCPA) and the Grupo Hospitalar Conceição (protocols 11-0097 and 11-027, respectively). The study involved minimum risk for the participants, in accordance with Brazilian Ministry of Health/National Health Council resolution 466/2012.

Between 2011 and 2016, a convenience sample of mother-infant pairs was recruited 24 to $48 \mathrm{~h}$ postpartum from three municipal public hospitals in Porto Alegre, Brazil (HCPA, Hospital Fêmina, and Hospital Nossa Senhora da Conceição). The mothers gave written informed consent prior to participation.
The intention-to-treat approach was used in the initial recruitment and sample selection, since participants were allocated into a control group and an adverse intrauterine group that was subdivided as follows: a) diabetes mellitus: puerperal women diagnosed with type 1 , type 2 or gestational diabetes mellitus [24]; b) hypertensive disorders: puerperal women diagnosed with preeclampsia, chronic hypertension with superimposed preeclampsia, chronic or gestational hypertension [25]; c) smoking: women who smoked during gestation; and d) intrauterine growth restriction: women whose newborns were below the 5th percentile of the Alexander Growth Curve [26]. For the present study, however, the analyses were carried out without this subdivision, since domestic violence may have occurred prior to the presented outcomes.

Puerperal women with HIV, preterm newborns, congenital diseases or who required hospitalization were excluded. Mothers who, after personal or telephone contact, stated they had no further interest in participation, as well as participants who failed to answer the domestic violence questionnaire, were considered missing. Data collection was performed by trained interviewers who underwent periodic retraining.

\section{Variables}

Data on maternal age, education, marital status, planned pregnancy, number of children, number of prenatal visits, breastfeeding and complementary feeding were collected through questionnaires prepared by the research group and administered in the third and sixth postpartum months at the mother's home and the HCPA Clinical Research Center, respectively.

Domestic violence during pregnancy was assessed with a self-report questionnaire developed by specialists [3]. The questionnaire was based on the Abuse Assessment Screen, [27] which has been translated to Portuguese and validated [28]. It was applied in the first and the sixth months postpartum through interviews conducted at the HCPA Clinical Research Center. It involved four main questions assessing the type of violence suffered: physical (physical aggression or assault with weapons); psychological (verbal aggression); and sexual (forced sexual intercourse). If these questions were answered in the affirmative, the women were asked whether the violence took place during pregnancy or not. The participant was considered to have suffered domestic violence while pregnant if she responded in the affirmative to any type of violence.

In the present study, early complementary feeding was defined as the introduction of foods prior to or at 3 months of age, depending on the date scheduled for the interview. This was evaluated with a questionnaire applied at home in the third month postpartum. In this 
questionnaire, information on breastfeeding was also collected and divided into two categories: infants who were exclusively breastfed (infants who received only breast milk); and infants who were breastfed (infants who received breast milk concomitantly with another type of milk or infant formula).

In all analyses, maternal age was considered full years at the time of the interview and was calculated as the difference between the date of birth reported by the mother and the date of the interview. Maternal education was calculated as complete years of study at the time of the postpartum interview. The participant's marital status was divided into two categories: living with a partner (married or living together) or living without a partner (single, separated, divorced, widowed or unmarried). Planned pregnancy was calculated as either yes or no. In all analyses, the number of children included all self-reported daughters and sons, including the newborn. The number of prenatal visits was considered the number of prenatal consultations registered in the mother's Ministry of Health documents.

\section{Statistical analyses}

The data were analyzed in SPSS (Statistical Package for Social Sciences) 18.0. Continuous variables were described as mean and standard deviation $( \pm \mathrm{SD})$, while categorical variables were presented as absolute and relative frequencies. Student's $t$-test was used to compare domestic violence with continuous variables (maternal age and maternal education), while the chi-square test was used for categorical variables (marital status and breastfeeding at 3 months). A Cox regression model was used to evaluate factors associated with early complementary feeding over time. The significance level was set at $5 \%(p<0.05)$.

\section{Results}

A sample of 232 mother-infant pairs was evaluated, because they had information on domestic violence during pregnancy. The mothers' mean age was $27.4 \pm 6.7$ years, with $9.6 \pm 2.7$ years of education. Sample characteristics are shown in Table 1.

Regarding domestic violence during pregnancy, 15.1\% (35) of the mothers reported suffering some form of violence. The distribution of maternal characteristics in relation to domestic violence during pregnancy is described in Table 2 . There was a statistically significant difference in maternal education and marital status $(p=$ 0.044 and $p=0.018$, respectively) between women who reported having suffered violence and those who did not.

A total of $33.2 \%$ (77) of the mothers reported having begun complementary feeding before the infant completed 3 months of life (mean days until onset $72.86 \pm$ 17.83), of whom $22.1 \%$ (17) reported suffering some type of violence during pregnancy. Of all mothers who
Table 1 Sample characterization- IVAPSA study. Porto Alegre (2011-2016)

\begin{tabular}{|c|c|}
\hline Variables & \\
\hline Maternal age (years) $^{a}$ & $27.4 \pm 6.7$ \\
\hline Maternal education (years) ${ }^{a}$ & $9.6 \pm 2.7$ \\
\hline \multicolumn{2}{|c|}{ Domestic violence during pregnancy ${ }^{b}$} \\
\hline No & $197(84.9)$ \\
\hline Yes & $35(15.1)$ \\
\hline Total & 232 \\
\hline \multicolumn{2}{|l|}{ Marital status $^{\mathbf{b}}$} \\
\hline With partner & $194(83.6)$ \\
\hline Without partner & $38(16.4)$ \\
\hline Total & 232 \\
\hline \multicolumn{2}{|l|}{ Breastfeeding at 3 months ${ }^{b}$} \\
\hline Exclusive breastfeeding & $86(37.1)$ \\
\hline Breastfeeding & $128(55.2)$ \\
\hline Total $^{c}$ & 214 \\
\hline \multicolumn{2}{|l|}{ Planned pregnancy ${ }^{b}$} \\
\hline Yes & $91(39.2)$ \\
\hline No & $141(60.8)$ \\
\hline Total & 232 \\
\hline Number of children* a & $2.58 \pm 1.6$ \\
\hline Number of prenatal visits ${ }^{a}$ & $8.45 \pm 3.2$ \\
\hline
\end{tabular}

${ }^{\mathrm{a}}$ Mean $\pm \mathrm{SD} ;{ }^{\mathrm{b}}$ Absolute and relative frequency (\%); ${ }^{\mathrm{c}}$ This variable was calculated as 214 participants, since 18 participants did not provide this information. IVAPSA Impact of perinatal environment variations on the health of the newborn in the first 6 months of life. * This variable includes the children evaluated in this study

reported domestic violence during pregnancy, 51.4\% (18) did not initiate early feeding.

Table 3 presents the univariate and multivariate analyses for early complementary feeding through Cox regression analysis. The dependent variable was the time in days at which each child began complementary feeding. In the univariate analysis, the number of children and the number of prenatal consultations were not statistically significant. The significant variables, including reported domestic violence, were included in the multivariate analysis. Following the adjusted analysis, when the combined effect of the variables was considered, domestic violence, planned pregnancy and marital status lost statistical significance $(p=0.535, p=0.054$ and $p=0.614$, respectively). It was found that each year of maternal age and maternal education, as well as exclusive breastfeeding at 3 months of age were protective factors against early complementary feeding $(\mathrm{HR}=$ $0.963, \mathrm{HR}=0.890, \mathrm{HR}=0.469$, respectively).

\section{Discussion}

In the present study, no significant association was found between early complementary feeding and 
Table 2 Distribution of maternal characteristics in relation to domestic violence during pregnancy -IVAPSA study. Porto Alegre (2011-2016)

\begin{tabular}{|c|c|c|c|c|}
\hline \multirow[t]{2}{*}{ Variables } & \multirow[b]{2}{*}{ Total } & \multicolumn{2}{|c|}{ Domestic Violence } & \multirow[b]{2}{*}{$\boldsymbol{p}$-value ${ }^{\text {a }}$} \\
\hline & & Yes & No & \\
\hline Maternal age (years) $^{\mathbf{b}}$ & $27.4( \pm 6.7)$ & $25.4( \pm 7.2)$ & $27.7( \pm 6.6)$ & 0.055 \\
\hline Maternal education (years) ${ }^{b}$ & $9.6( \pm 2.7)$ & $8.7( \pm 2.9)$ & $9.7( \pm 2.6)$ & 0.044 \\
\hline \multicolumn{5}{|l|}{ Breastfeeding $^{c}$} \\
\hline EBF & $86(40.2)$ & $10(32.3)$ & $76(41.5)$ & \multirow[t]{2}{*}{0.438} \\
\hline $\mathrm{BF}$ & $128(59.8)$ & $21(67.7)$ & $107(58.5)$ & \\
\hline \multicolumn{5}{|l|}{ Marital status $^{c}$} \\
\hline With partner & $194(83.6)$ & $24(68.6)$ & $170(86.3)$ & \multirow[t]{2}{*}{0.018} \\
\hline Without partner & $38(16.4)$ & $11(13.7)$ & $27(31.4)$ & \\
\hline Early Introduction to Complementary Feeding & $77(33.2)$ & $17(22.1)$ & $60(77.9)$ & - \\
\hline Number of children ${ }^{b}$ & $2.58( \pm 1.6)$ & $2.29( \pm 1.3)$ & $2.60( \pm 1.6)$ & 0.268 \\
\hline Number of prenatal visits ${ }^{b}$ & $8.45( \pm 3.2)$ & $8.43( \pm 3.5)$ & $8.44( \pm 3.1)$ & 0.986 \\
\hline \multicolumn{5}{|l|}{ Planned pregnancy ${ }^{c}$} \\
\hline Yes & $91(39.2)$ & $11(12.1)$ & $80(87.9)$ & \multirow[t]{2}{*}{0.402} \\
\hline No & $141(60.8)$ & $24(17)$ & $117(83)$ & \\
\hline
\end{tabular}

${ }^{\mathrm{a}}$ Student's t-test and chi-squared test; ${ }^{\mathrm{b}}$ Mean $\pm \mathrm{SD},{ }^{\mathrm{c}}$ Absolute and relative frequencies (\%). IVAPSA Impact of perinatal environment variations on the health of the newborn in the first 6 months of life, EBF Exclusive Maternal Breastfeeding, BF Breastfeeding

domestic violence during pregnancy. Most participants who began early complementary feeding reported no violence during pregnancy. The prevalence of early complementary feeding was $33.2 \%$, which was higher than the $7 \%$ found by Magarey et al. [29]. This difference could be explained by the fact that our sample of mothers were younger and had less education. This is in line with previous publications that have found an association between low education, lower maternal age, and early complementary feeding [14, 15, 30-32].

Domestic violence, particularly from an intimate partner, has been studied as a risk factor for inadequate breastfeeding practices [7-10], and such practices are related to the introduction of complementary feeding. We found that, following a multivariate analysis, exclusive breastfeeding at 90 days was a protective factor against early complementary feeding. Thus, there is a greater risk of early complementary feeding in infants who are not exclusively breastfed [14, 30,33]. There was no significant association between exclusive breastfeeding and domestic violence during pregnancy.

According to previous studies, maternal education is associated with domestic violence in pregnancy. Lower levels of maternal education have been associated with a higher prevalence of domestic violence during pregnancy $[4,5,33]$. This finding was confirmed in the present study: domestic violence during pregnancy was significantly more prevalent in women with a low education level. The number of previous children (i.e. whether or not the mother is primiparous) was not associated with

Table 3 Variables associated with early introduction of complementary feeding in infants - IVAPSA study. Porto Alegre (2011-2016)

\begin{tabular}{|c|c|c|c|c|c|c|}
\hline \multirow[t]{2}{*}{ Variables } & \multicolumn{3}{|c|}{ Univariate Analysis* } & \multicolumn{3}{|c|}{ Multivariate Analysis* } \\
\hline & $\overline{\mathrm{HR}}$ & $95 \% \mathrm{Cl}$ & $p$-value ${ }^{a}$ & Adjusted HR & Adjusted 95\% Cl & Adjusted $\boldsymbol{p}$-value $^{\mathbf{a}}$ \\
\hline Maternal age & 0.94 & {$[0.91 ; 0.98]$} & 0.001 & 0.96 & {$[0.93 ; 1.00]$} & 0.039 \\
\hline Maternal education & 0.86 & {$[0.81 ; 0.94]$} & $<0.001$ & 0.89 & {$[0.81 ; 0.97]$} & 0.009 \\
\hline Breastfeeding & 2.34 & {$[1.38 ; 3.98]$} & 0.002 & 0.46 & {$[0.27 ; 0.80]$} & 0.005 \\
\hline Marital status & 1.72 & {$[1.03 ; 2.90]$} & 0.039 & 1.16 & {$[0.65 ; 2.06]$} & 0.614 \\
\hline Domestic violence & 1.74 & {$[1.01 ; 2.98]$} & 0.044 & 1.21 & {$[0.66 ; 2.23]$} & 0.535 \\
\hline Number of children & 1.04 & {$[0.91 ; 1.19]$} & 0.531 & 1.03 & {$[0.90 ; 1.17]$} & 0.649 \\
\hline Number of PN visits & 0.97 & {$[0.91 ; 1.04]$} & 0.490 & 0.99 & {$[0.92 ; 1.05]$} & 0.763 \\
\hline Planned pregnancy & 0.62 & {$[0.38 ; 0.99]$} & 0.045 & 0.62 & {$[0.39 ; 1,00]$} & 0.054 \\
\hline
\end{tabular}

${ }^{a}$ Cox regression. IVAPSA Impact of perinatal environment variations on the health of the newborn in the first 6 months of life, $H R$ Risk ratio, $95 \% C l 95 \%$ confidence interval, $P N$ prenatal. * All variables included in the univariate analysis were included in the multivariate analysis. The dependent variable was the time in days at which each child began complimentary feeding 
domestic violence or early complementary feeding, nor were the number of prenatal visits, which could indicate whether the mother received professional guidance regarding postpartum care (including nutrition). Planned pregnancy was not associated with domestic violence or early complementary feeding (in the adjusted analysis), indicating that planning is not a protective or risk factor for domestic violence or early complementary feeding.

The relationship between marital status and domestic violence during pregnancy revealed that the presence of a partner was significantly associated with domestic violence, a result also found by Santos et al. [2]. Nevertheless, other authors have not found the same association, observing instead that exposure to violence was more prevalent in women who did not have a partner [10, 34]. There was no also significant association between complementary feeding and marital status after the adjusted analysis.

We found that each year of maternal education becomes a protective factor for the early introduction of complementary feeding. In fact, a number of studies have found low education to be associated with early complementary feeding $[15,16,29]$. Considering its long-term importance for the infant's health, maternal access to infant feeding information at an appropriate reading level is a clear necessity, as has been strongly demonstrated in the literature [7, 15-19]. Another protective factor for early complementary feeding was maternal age: the older the mother, the lower the probability of beginning complementary feeding before 3 months of age. Previous research on the determinants of infant feeding practices has shown an association between early complementary feeding and young mothers $[15,31]$. Similar to our findings. Scott et al. found that maternal age continued to be associated with early complementary feeding, even after adjustment for possible confounding factors [31]. It can be suggested that the lower the mother's age, the greater the probability that she is insecure about her ability to care for the child, since older mothers may have more experience or previous children, which would facilitate introducing complementary feeding at a more appropriate time.

The main limitations and weaknesses of this study involved the domestic violence data, since the mothers were the sole source of information, and underreporting may have occurred. Consequently, the small number of participants who reported suffering domestic violence during pregnancy decreased the intensity of the observed associations. Some women might not have felt safe about reporting domestic violence during pregnancy due to personal issues such as embarrassment, fear, and economic dependence, or to social issues such as family privacy, victim blaming, etc. [35]. In a recent study by Caleyachetty et al. [36], underreporting of domestic violence was also cited as a limitation, which also could have attenuate their findings [36]. On the other hand, our study's strength is that it has explored, in an unprecedented fashion, the relationship between domestic violence during pregnancy and early complementary feeding. In the future, a mechanism for determining the impact of an environment of violence on infant feeding could be explored.

\section{Conclusion}

Thus, there was no relationship between domestic violence against pregnant women and early complementary feeding, since violence was only a risk factor for the early complementary feeding in the univariate analysis, but was not significant when adjusted for other factors. However, these conclusions should be interpreted with caution, since the sample size of victims was small.

A previous study also found that exposure to violence did not significantly affect complimentary feeding prior to 6 months of age [21]. An association between domestic violence and complementary feeding has not been established in greater detail due to the lack of studies on this subject [37].

The present study highlights the importance of identifying domestic violence risk groups during prenatal care, as well as during postpartum and childcare consultations. Through the diligence of maternal and child health professionals, actions targeting the early detection of domestic violence during pregnancy could be developed, preventing future aggravations to maternal and child health and identifying mothers at risk of early weaning/complementary feeding.

Although domestic violence during pregnancy has been the subject of many studies, new research could clarify the interaction between domestic violence and the onset of complementary feeding.

\section{Abbreviations \\ HCPA: Hospital de Clínicas de Porto Alegre; IVAPSA: Impact of perinatal environment variations on the health of the newborn in the first 6 months of life; SD: Standard Deviation; HR: Risk ratio; EBF: Exclusive Maternal Breastfeeding; BF: Breastfeeding; SPSS: Statistical Package for Social Sciences; HIV: Human Immunodeficiency virus}

\section{Acknowledgements}

We would like to thank the researchers from the IVAPSA group, who were fully involved in the rationale and design of the IVAPSA project and contributed to data collection and analysis in all its studies.

\section{Authors' contributions}

GLC participated in the literature review, analysis and writing of the article and performed statistical analysis. JRB participated in the study design, analysis and writing of the article.

VLB was involved in study conception, design, and coordination and helped prepare the manuscript. CHS was involved in study conception, design, and coordination and helped to prepare the manuscript. MZG was involved in study conception, design, and coordination and helped to prepare the manuscript. All authors read and approved the final manuscript. 


\section{Authors' information}

GLC: M.S. in Child and Adolescent Health, Universidade Federal do Rio Grande do Sul (UFRGS).

JRB: Assistant Professor, Department of Nutrition, Child and Adolescent Health Program and Food, Nutrition and Health Program, Center for Child and Adolescent Health Studies, Hospital de Clínicas de Porto Alegre (HCPA), Universidade Federal do Rio Grande do Sul (UFRGS).

VLB: Assistant Professor, Department of Nutrition, Food, Nutrition and Health Program, Hospital de Clínicas de Porto Alegre (HCPA), Universidade Federal do Rio Grande do Sul (UFRGS).

CHS: Associate Professor, Department of Pediatrics and Child and Adolescent Health Program, Center for Child and Adolescent Health Studies, Hospital de Clínicas de Porto Alegre (HCPA), Universidade Federal do Rio Grande do Sul (UFRGS).

MZG: Full Professor, Department of Pediatrics and Child and Adolescent Health Program, Center for Child and Adolescent Health Studies, Hospital de Clínicas de Porto Alegre (HCPA), Universidade Federal do Rio Grande do Sul (UFRGS).

\section{Funding}

The study was funded by FAPERGS/CNPq 10/0018.3 (National Council for Scientific and Technological Development), PRONEX 2009 (Support Program for Centers of Excellence), FIPE/HCPA (Research Incentive Fund and Hospital de Clínicas de Porto Alegre) and CAPES (Commission for the Improvement of Higher Education Personnel). The institution reviewed the proposal, provided laboratory space and equipment, data analysis and manuscript development.

\section{Availability of data and materials}

The dataset used and analysed during the current study are available from the corresponding author on reasonable request.

\section{Ethics approval and consent to participate}

This study was approved by the Research Ethics Committees of the Hospital de Clínicas de Porto Alegre and the Grupo Hospitalar Conceição, (protocols 11-0097 and 11-027, respectively). Participants were included only after providing written informed consent.

\section{Consent for publication}

Not applicable.

\section{Competing interests}

The authors declare that they have no competing interests.

Received: 3 October 2019 Accepted: 30 July 2020

Published online: 05 August 2020

\section{References}

1. Krantz G, Garcia-Moreno C. Violence against women. J Epidemiol Community Health. 2005;59:818-21.

2. Santos SA, Lovisi GM, Valente CCB, Legay L, Abelha L. Violência doméstica durante a gestação: um estudo descritivo em uma unidade básica de saúde no Rio de Janeiro. Cad Saúde Colet. 2010;18(4):483-93.

3. Nunes MA, Ferri CP, Manzolli P, Soares RM, Drehmer M, Buss C, et al. Nutrition, mental health and violence: from pregnancy to postpartum cohort of women attending primary care units in southern Brazil - ECCAGE study. BMC Psychiatry. 2010;10(1):66.

4. Audi CAF, Segall-Corrêa AM, Santiago SM, Pérez-Escamilla R. Adverse health events associated with domestic violence during pregnancy among Brazilian women. Midwifery. 2012;28(4):416-21.

5. Mariano LMB, Monteiro JCS, Stefanello J, Gomes-Sponholz FA, Oriá MOB, Nakano MAS. Aleitamento materno exclusivo e autoeficácia materna entre mulheres em situação de violência por parceiro íntimo. Texto Contexto Enferm. 2016;25(4):1-10.

6. Sobkoviak RM, Yount KM, Halim N. Domestic violence and child nutrition in Liberia. Soc Sci Med. 2012;74:103-11.

7. Mezzavilla RS, Ferreira MF, Curioni CC, Lindsay AC, Hasselmann MH. Intimate partner violence and breastfeeding practices: a systematic review of observational studies. J Pediatr. 2017;94:226-3.
8. Hasselmann M.H., Lindsay A.C., Surkan P.J., Vianna G.V. \& Werneck G.L. Intimate partner violence and early interruption of exclusive breastfeeding in the first three months of life. Cad. Saúde Pública, Rio de Janeiro. 2016;32.

9. Bullock LF, Libbus MK, Sable MR. Battering and breastfeeding in a WIC population. Can J Nurs Res. 2011;32:43-56.

10. Silverman JG, Decker MR, Reed E, Raj A. Intimate partner violence around the time of pregnancy: association with breastfeeding behavior. J Women's Health. 2006;15(8):934-40.

11. FAO, IFAD, UNICEF, WFP and WHO. The state of food security and nutrition in the World 2019. Safeguarding against economic slowdowns and downturns. Rome: FAO; 2019.

12. BRASIL. Ministério da Saúde. Secretaria de Atenção a Saúde. Departamento de Ações Programáticas e Estratégicas. II Pesquisa de Prevalência de Aleitamento Materno nas Capitais Brasileiras e Distrito Federal / Ministério da Saúde, Secretaria de Atenção a Saúde, Departamento de Ações Programáticas e Estratégicas. - Brasília: Editora do Ministério da Saúde, 2009.

13. WORLD HEALTH ORGANIZATION (WHO). Complementary feeding: report of the global consultation, and summary of guiding principles for complementary feeding of the breastfed child. Global Consultation on Complementary Feeding. 2002:1-24.

14. BRASIL. Ministério da Saúde. Secretaria de Atenção à Saúde. Departamento de Atenção Básica. Saúde da criança: aleitamento materno e alimentação complementar / Ministério da Saúde, Secretaria de Atenção à Saúde, Departamento de Atenção Básica. - 2. ed. Braślia: Ministério da Saúde, 2015.

15. Tokuda-Tatone F, Dubois L, Girard M. Psychosocial determinants of the early introduction of complementary foods. Health Educ Behav. 2009; 36(2):302-20

16. Clayton HB, Li R, Perrine CG, Scanlon KS. Prevalence and reasons for introducing infants early to solid foods: variations by Milk feeding type. Pediatrics. 2013;131(4):1108-14.

17. Vehapoglu A, Yazıcı M, Demir AD, Turkmen S, Nursoy M, Ozkaya E. Early infant feeding practice and childhood obesity: the relation of breast-feeding and timing of solid food introduction with childhood obesity. J Pediatr Endocr Met. 2014;27(11):1181-7.

18. Pearce J, Taylor MA, Langley-Evans SC. Timing of the introduction of complementary feeding and risk of childhood obesity: a systematic review. Int J Obes. 2013:37:1295-306.

19. Daniels L, Mallan KM, Fildes A, Wilson J. The timing of solid introduction in an 'obesogenic' environment: a narrative review of the evidence and methodological issues. Aust N Z J Public Health. 2015;39(4):366-73.

20. Fewtrell M, Bronsky J, Campoy C, Domellöf M, Embleton N, Mis NF, et al. Complementary feeding: a position paper by the European Society for Paediatric Gastroenterology, Hepatology, and nutrition (ESPGHAN) committee on nutrition. JPGN. 2017;64:119-32.

21. Zureick-Brown S, Lavilla K, Yount KM. Intimate partner violence and infant feeding practices in India: a cross-sectional study. Matern Child Nutr. 2015; 11:792-802.

22. Bernardi JR, Ferreira CF, Nunes M, Silva CH, Bosa VL, Silveira PP, et al. Impact of perinatal different intrauterine environments on child growth and development in the first six months of life--IVAPSA birth cohort: rationale, design, and methods. BMC Pregnancy Childbirth. 2012;12:12-25.

23. ICB W, Bernardi JR, Nunes M, Marcelino TB, Bosa VL, Michalowski MB, et al. Impact of perinatal different intrauterine environments on child growth and development in the first six months of life: Profile of IVAPSA Study. (Preprint). JMIR Res Protoc. 2018;8:12970.

24. SOCIEDADE BRASILEIRA DE DIABETES (SBD). Diretrizes da Sociedade Brasileira de Diabetes (2015-2016). São Paulo, 2016. Available at: http://www. diabetes.org.br. Accessed 02 June 2018.

25. SOCIEDADE BRASILEIRA DE CARDIOLOGIA (SBC). 7a Diretriz Brasileira de Hipertensão Arterial. 2016. Available at: http://publicacoes.cardiol.br/2014/ diretrizes/2016/05_HIPERTENSAO_ARTERIAL.asp. Accessed 02 June 2018.

26. Alexander GR, Himes JH, Kaufman RB, Mor J, Kogan M. A United States national reference for fetal growth. Obstet Gynecol. 1996;87(2):163-8.

27. McFarlane J, Parker B, Soeken K, Bullock L. Assessing for abuse during pregnancy - severity and frequency of injuries and associated entry into prenatal-care. J Am Med Assoc. 1992;267:3176-8.

28. Reichenheim ME, Moraes $\mathrm{CL}$, Hasselmann MH. Semantic equivalence of the Portuguese version of the abuse assessment screen tool used for the screening of violence against pregnant women. Rev Saude Publica. 2000;34:610-6. 
29. Magarey A, Kavian F, Scott JA, Daniels L. Feeding mode of Australian infants in the first 12 months of life: an assessment against national breastfeeding indicators. J Hum Lact. 2015;32(4):95-104.

30. Rebhan B, Kohlhuber M, Schwegler U, Koletzko BV, Fromme H. Infant feeding practices and associated factors through the first 9 months of life in Bavaria, Germany. J Pediatr Gastroenterol Nutr. 2009:49(4):467-73.

31. Scott JA, Binns CW, Graham Kl, Oddy WH. Predictors of the early introduction of solid foods in infants: results of a cohort study. BMC Pediatr. 2009;9(1):60

32. Alzaheb RA. Factors associated with the early introduction of complementary feeding in Saudi Arabia. Int J Environ Res Public Health. 2016;13(7):702

33. Moraes $\mathrm{CL}$, Reichenheim ME. Domestic violence during pregnancy in Rio de Janeiro, Brazil. Int J Gynecol Obstet. 2002;79:269-77.

34. Sorbo MF, Lukasse M, Brantsæter AL, Grimstad H. Past and recent abuse is associated with early cessation of breast feeding: results from a large prospective cohort in Norway. BMJ Open. 2015:5:12.

35. Gracia E. Unreported cases of domestic violence against women: towards an epidemiology of social silence, tolerance, and inhibition. J Epidemiol Community Health. 2004;58(7):536-7.

36. Caleyachetty R., Uthman O.A., Bekele H.N., Martín-Cañavate R., Marais D., Coles J., et al. Maternal exposure to intimate partner violence and breastfeeding practices in 51 low-income and middle-income countries: A population-based cross-sectional study. PLoS Med. 2019;16(10):e1002921.

37. Yount KM, DiGirolamo AM, Ramakrishnan U. Impacts of domestic violence on child growth and nutrition: a conceptual review of the pathways of influence. Soc Sci Med. 2011;72:1534-54.

\section{Publisher's Note}

Springer Nature remains neutral with regard to jurisdictional claims in published maps and institutional affiliations.

Ready to submit your research? Choose BMC and benefit from:

- fast, convenient online submission

- thorough peer review by experienced researchers in your field

- rapid publication on acceptance

- support for research data, including large and complex data types

- gold Open Access which fosters wider collaboration and increased citations

- maximum visibility for your research: over $100 \mathrm{M}$ website views per year

At BMC, research is always in progress.

Learn more biomedcentral.com/submissions 